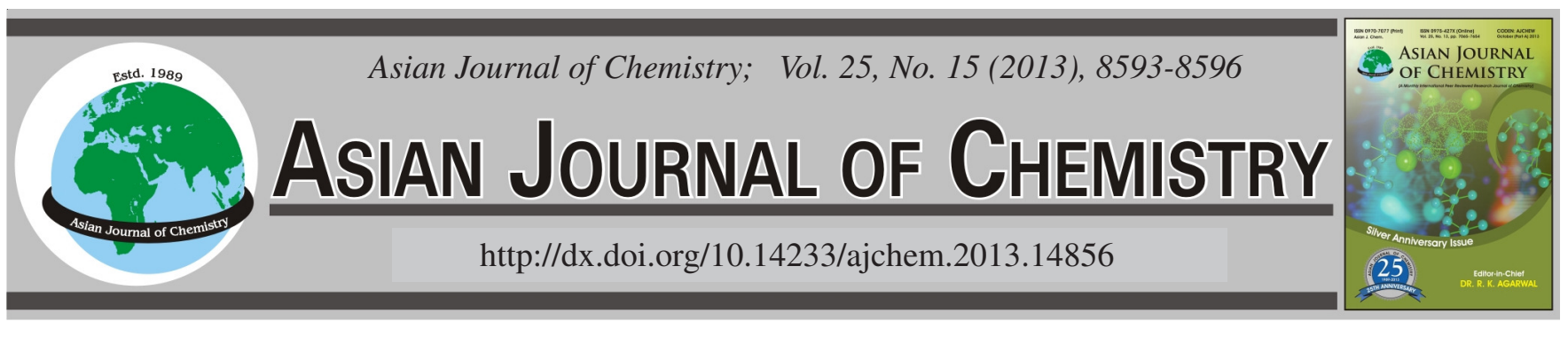

\title{
Determination of Monoamine Neurotransmitters in Brains of Paraquat-Induced Mouse by HPLC with Electrochemical Detection
}

\author{
Siyuan Bi, Wei Wang, Kaogi Lian, Xiangdong Xu, Lingmei Niu, Hongmei Shi and Weijun Kang*
}

School of Public Health, Hebei Medical University, Shijiazhuang 050017, P.R. China

*Corresponding author: Tel/Fax: +86 311 86265754; E-mail: kangwj@hebmu.edu.cn; huangpuchangshou@163.com

(Received: 21 November 2012;

Accepted: 26 August 2013)

AJC-14003

\begin{abstract}
A liquid chromatography-electrochemical detection method for the quantification of dopamine, 3,4-dihydroxyphenyl acetic acid, homovanillic acid, 3-methoxy-4-hydroxy phenylglycol, 5-hydroxytryptamine and 5-hydroxyindole-3-acetic acid was presented. The neurotransmitters were analyzed by an liquid chromatography on a $\mathrm{C}_{18}$ column with an electrochemical detection. Brain samples with $1 \mathrm{~mL}$ of $5 \%$ sulfosalicylic acid were homogenized and centrifuged, then for analysis. This method exhibited excellent linearity for all of the analytes with regression coefficients higher than 0.99 . The limit of detection values for dopamine, 3,4-dihydroxyphenyl acetic acid, homovanillic acid, 3-methoxy-4-hydroxy phenylglycol, 5-hydroxytryptamine and 5-hydroxyindole-3-acetic acid were 2.2, 3.0, 1.7, 3.7, 0.9 and $1.0 \mathrm{ng} / \mathrm{mL}$, respectively. The precision results were expressed as relative standard deviation, ranging from 2.1 to $3.8 \%$ for intraday and from 2.8 to $4.8 \%$ for the inter-day. The recoveries were ranged from 88.6 to $94.5 \%$ for intra-day and from 86.6 to $93.9 \%$ for the inter-day. This novel HPLC-ECD approach is precise, highly sensitive, specific and sufficiently simple.

Key Words: Monoamine neurotransmitters, Paraquat, Mouse brain, HPLC, Electrochemistry detector.
\end{abstract}

\section{INTRODUCTION}

Neurotransmitters and their metabolites are widely distributed in the central nervous system and the peripheral body fluids of mammals. They are known to play a significant role in the nervous system for numerous organisms. Monoamine neurotransmitters include 5-hydroxytryptamine, dopamine and the acidic metabolites 5-hydroxyindole-3-acetic acid, 3-methoxy4-hydroxy phenylglycol, 3,4-dihydroxyphenylacetic acid and homovanillic acid. Their molecular structures are shown in Fig. 1. The monitoring of neurotransmitters and their metabolites is an essential tool for elucidating normal and pathological neural system functions. Trace-level measurements in biological specimens are especially important in studying the neurotransmitter metabolism profile and the role of neurotransmitters and their metabolites in neurophysiology, behavioural effects, pathology, disease diagnosis and control because their changes have been associated with various diseases and disorders such as Alzheimer's disease ${ }^{1}$, epilepsy ${ }^{2}$, Down's syndrome ${ }^{3}$, depression $^{4}$ and Parkinson's disease ${ }^{5}$.

Paraquat (1,1'-dimethyl, 4,4'-bipyridium) is a herbicide that is wildly used in over 130 counties $^{6}$, which has caused many fatalities since it was first marketed about 50 years ago. It is known that lung is the primary target organ of paraquat, in fact, the paraquat can be harm to the other organs such as kidney, liver, heart and brain. Up to now, there is no accepted biological validation of or laboratory test for the neurotransmitters of paraquat-poisoning varieties in mammal brains. Level changes of neurotransmitters and their metabolites in the brain are the hallmark of neurotransmission deficiencies. Analysis of them may provide not only a clue for diagnosis but also information about prognosis and treatment monitoring.

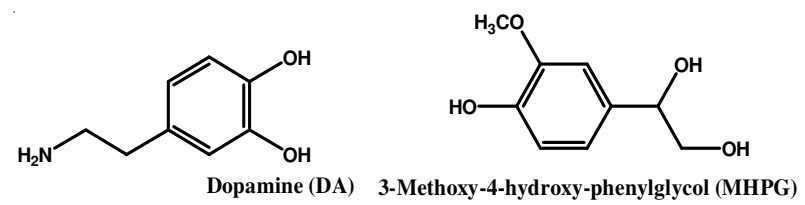<smiles>NCCc1c[nH]c2ccc(O)cc12</smiles>

5-Hydroxytryptamine (5-HT)<smiles>O=C(O)Cc1ccc(O)c(O)c1</smiles>

3,4-Dihyoxyphenylacetic acid (DOPAC)<smiles>O=C(O)Cc1c[nH]c2ccc(O)cc12</smiles><smiles>COc1cc(CC(=O)O)ccc1O</smiles>

Homovanillic acid (HVA)

Homovanillic acid
5-Hydroxyindole-3-acetic (5-HIAA) 
High performance liquid chromatography or capillary electrophoresis coupled with various detecting techniques, such as ultraviolet ${ }^{7}$, fluorescence detection ${ }^{8}$, laser-induced fluorescence detection ${ }^{9}$ and mass spectrometry ${ }^{10}$, have been widely used for the determination of monoamine neurotransmitters. These methods have their own limitations. UV detection is not sensitive to or selective for monoamines. Fluorescence detection, which usually requires derivatization, is sometimes compromised by interfering substances and peak overlapping. HPLC-MS and CE-MS are too expensive for a common school or hospital and lack sensitivity in blood tests. High-performance liquid chromatography with electrochemical detection ${ }^{11-13}$ has also been used, because of its simple operation, low cost and the lack of need for sample derivatization. However, the biological samples are liquid such as mammal plasma. This paper described a novel method to detect neurotransmitters in mouse brains and detected the neurotransmitters in normal and paraquat-induced mice's brains. Also by this experiment, the effect of paraquat in mammal's nervous system was discussed.

\section{EXPERIMENTAL}

Dopamine, 3-methoxy-4-hydroxyphenyletilenglycol, 3,4dihydroxyphenylacetic acid, 4-hydroxy-3-methoxyphenylacetic acid, 5-hydroxytryptamine and 5-hydroxyindoleacetic acid were purchased from Sigma (St. Louis, MO, USA). Methanol (HPLC grade) was purchased from Burdick and Jackson (Honeywell Int. Inc, USA). Sodium citrate $\left(\mathrm{C}_{6} \mathrm{H}_{5} \mathrm{Na}_{3} \mathrm{O}_{7} \cdot 2 \mathrm{H}_{2} \mathrm{O}\right)$, Sulfosalicylic acid, hydrochloric acid and sodium metabisulphite were all of analytical grade and purchased from Yongda Chemical Factory (Tianjin, China). All the water in these experiments was ultra-pure water (18.2 $\mathrm{M} \Omega \mathrm{cm}$ ) and was obtained from a Millipore (Milford, MA, USA) Milli-Q apparatus.

Stock solutions $(1 \mathrm{mg} / \mathrm{mL})$ of neurotransmitters were prepared by dissolving $20 \mathrm{mg}$ of each pure substance, $160 \mathrm{mg}$ of $\mathrm{NaCl}, 20 \mathrm{mg}$ of sodium metabisulphite and $100 \mu \mathrm{L}$ of $37 \%$ $\mathrm{HCl}$ in $20 \mathrm{~mL}$ of doubly distilled water. This saline solution, prepared at acidic $\mathrm{pH}$ in the presence of metabisulfite, an antioxidant, avoided degradation of the analytes as previously reported $^{14}$. Working solutions were freshly prepared by diluting standard stock solutions with ultra pure water. All solutions were stored in a refrigerator at $4{ }^{\circ} \mathrm{C}$. Solution A: $5 \%$ sulfosalicylic acid: $5 \mathrm{~g}$ Sulfosalicylic was dissolved acid in $95 \mathrm{~mL}$ ultra pure water.

Animals and sample pre-treatment: Male Kunming mice (weight 40 45 g) were purchased from Animal Experimental Center, Hebei University, Shijiazhuang, China. The animals were allowed free access to water and food until the experiment started. The mice were picked up into 2 groups at random. Group1 was the CK group ( 7 mice) and group 2 was the paraquat-induced group. Paraquat-induced mice were received $10 \mathrm{mg} / \mathrm{kg}$ dose of paraquat, after 1, 3, 7, 14 and 21 days respectively, 7 of the mice were sacrificed, whose brains were taken out. The brains were flushed with $4{ }^{\circ} \mathrm{C}$ physiological saline to wash the blood away and were dried by filter papers. They were all weighted before pretreatment. Brain samples with $1 \mathrm{~mL}$ solution A were homogenized with a DY89- homogenizer (Scientz, Ningbo, China) for 5 min. All the materials were transferred into a $1.5 \mathrm{~mL}$ Eppendorf tube and centrifuged in a LG15-W centrifugal machine (Beijing medical centrifuge factory) at $4{ }^{\circ} \mathrm{C}, 10,000 \mathrm{r} / \mathrm{min} 10 \mathrm{~min}$. The supernatant needs to be filtrated by a $0.45 \mu \mathrm{m}$ filter membrane, $50 \mu \mathrm{L}$ of which can be injected into HPLC for analysis.

Detection method: The high performance liquid chromatography was an integrated system from Yilite, China, employed two P230 II pumps, a coulometric detector (Chenhua, Shanghai, China). Chromatography was performed at room temperature on a $200 \mathrm{~mm} \times 4.6 \mathrm{~mm}$ column, packed with $5 \mu \mathrm{m}$ SinoChrom ODS-BP (Yilite, Dalian, China). The mobile phase consisted of $10 \% \mathrm{v} / \mathrm{v} 0.02 \mathrm{M}$ sodium citrate in methanol. The $\mathrm{pH}$ was adjusted 4.25 by hydrochloric acid. The flow rate was $1.0 \mathrm{~mL} / \mathrm{min}$ isocratic and the injection volume was $20 \mu \mathrm{L}$. The applying potential of coulometric detector was set $0.75 \mathrm{~V}$.

Statistical analysis: Statistical analysis was performed by one-way ANOVA's $t$-test with SPSS 13.0 software. Data were expressed as mean \pm standard deviation at least four independent experiments. The level of significance was based on probability ${ }^{\#} \mathrm{P}<0.05 ;{ }^{*} \mathrm{P}<0.01$.

\section{RESULTS AND DISCUSSION}

Effect of mobile phase composition: In order to increase the efficiency of the chromatographic separation and to obtain shorter analysis times, some parameters of the mobile phase, such as inorganic/organic modifier content, or concentration and its $\mathrm{pH}$, were studied. Phosphate $\left(\mathrm{NaH}_{2} \mathrm{PO}_{4}\right)$ and citrate $\left(\mathrm{C}_{6} \mathrm{H}_{5} \mathrm{Na}_{3} \mathrm{O}_{7}\right)$ were the candidates of the inorganic salts. The peak areas of each neurotransmitter were not much different between the two salts, however, phosphate was easily crystallized and the pipe of HPLC was more likely blocked. So citrate was chosen, which concentration was adjusted from 10 to 50 $\mathrm{mM}$. According to the peak area size and $\mathrm{S} / \mathrm{N}, 20 \mathrm{mM}$ was suitable. The organic modifier content was adjusted from $5 \%$ to $20 \%$. When the methanol was $5 \%$, the analysis time was about $50 \mathrm{~min}$; while $20 \%$, the MPGH and 5-hydroxytryptamine cannot separate completely, so we chose $10 \%$ as the content of methanol. Hydrochloric acid was used to adjust the $\mathrm{pH}$ of mobile phase. A suitable $\mathrm{pH}$ can make the chromatography beautiful and brilliant and also decide the peak area size of the neurotransmitters. The $\mathrm{pH}$ was from 3.5 5.0 and the relationship between $\mathrm{pH}$ and peak area were shown in Fig. 2. $\mathrm{pH} 4.25$ was decided to be the appropriate $\mathrm{pH}$.

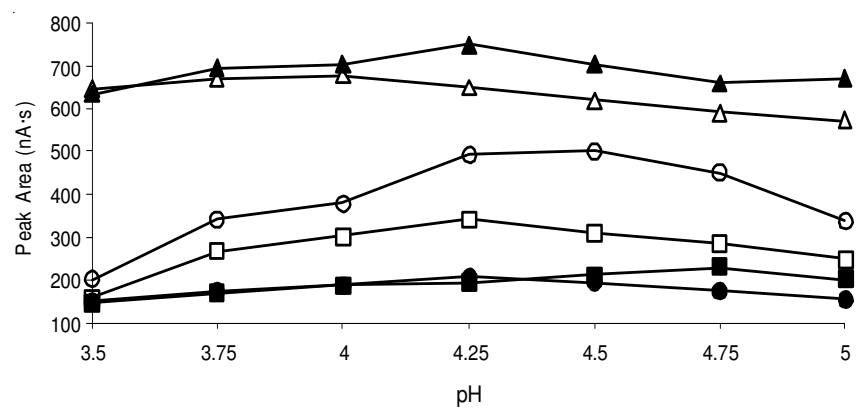

Fig. 2. Effect of $\mathrm{pH}$ value on peak area. Amount injection: $500 \mathrm{ng} \mathrm{mL} \mathrm{m}^{-1}$, injection volume: $20 \mu \mathrm{L}$; flow rate: $1 \mathrm{~mL} \mathrm{~min}^{-1}$. Symbols: (口) DA;




Selection of applying potentials: The electrochemical detector was composed by three electrodes i.e., reference electrode, auxiliary electrode and working electrode. When an applying potential were added on the working electrode, the substances in mobile phase and neurotransmitters were oxidized. An electronic signal was converted and transmitted to the computer. The applying potential was lower; the target analytes could not be oxidized; while higher, the other substances in the sample or mobile phase could disturb our determination. A proper potential was essential for this experiment, so it was investigated from 0.65 to $0.90 \mathrm{~V}$. The relationship between potential and peak area were shown in Fig. 3. At last, $0.75 \mathrm{~V}$ was decided to be the suitable potential in this study.

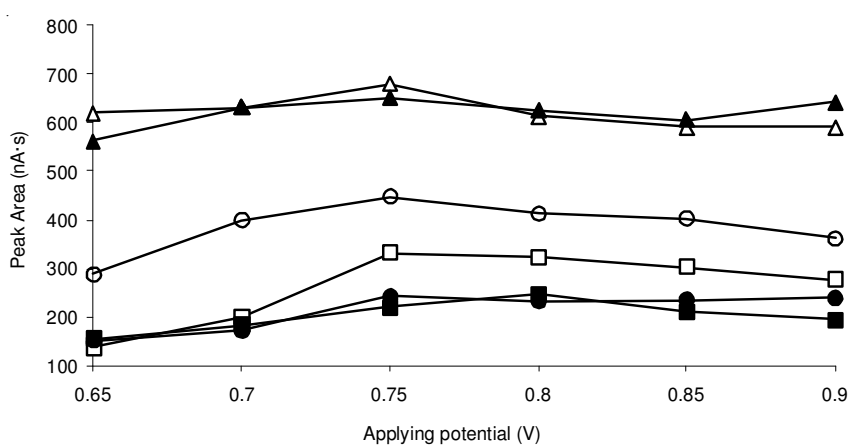

Fig. 3. Effect of applying potential on peak area. Amount injection: 500 ng $\mathrm{mL}^{-1}$, injection volume: $20 \mu \mathrm{L}$; flow rate: $1 \mathrm{~mL} \mathrm{~min}^{-1}$. Symbols:

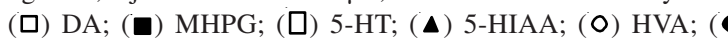
DOPAC

Linearity, limits of detection and reproducibility: The calibration curves of catecholamines and their metabolites showed linearity in the range studied $(10 \sim 1000 \mathrm{ng} / \mathrm{mL})$. The coefficients of correlation were higher than 0.99. The linear regression data are presented in Table- 1 . The limits of detection were based on a $3 \mathrm{~N} / \mathrm{a}$ ratio, where $\mathrm{N}$ is noise, defined as the difference between minimum and maximum signal intensities of the base line and a is the sensitivity or slope of calibration graph. As can be observed in Table-1, the detection limits vary from 0.9 to $3.7 \mathrm{ng} / \mathrm{mL}$. A typical chromatogram of a mixture of the analytes in optimal conditions is shown in Fig. 4. The reproducibility of the chromatographic method was estimated by making five repetitive injections of $500 \mathrm{ng} / \mathrm{mL}$ of the six analytes under optimal conditions. The relative standard deviations of the peak currents are summarized in Table-1.

\begin{tabular}{|c|c|c|c|c|c|}
\hline \multicolumn{6}{|c|}{$\begin{array}{c}\text { TABLE-1 } \\
\text { REGRESSION EQUATIONS OF THE SIX NTs }\end{array}$} \\
\hline Analytes & $\begin{array}{l}\text { Regression } \\
\text { equation }\end{array}$ & $\mathrm{R}^{2}$ & $\begin{array}{l}\text { Range } \\
(\mathrm{ng} / \mathrm{mL})\end{array}$ & $\begin{array}{c}\text { LOD } \\
(\mathrm{ng} / \mathrm{mL})\end{array}$ & $\begin{array}{r}\mathrm{RSD} \\
(\%) \\
\end{array}$ \\
\hline DA & $\begin{aligned} \mathrm{A}= & 0.3695 \mathrm{c}+ \\
& 17.17\end{aligned}$ & 0.999 & \multirow{6}{*}{$10-1000$} & 2.2 & 3.1 \\
\hline MHPG & $\begin{array}{c}A=0.2223 c+ \\
8.37\end{array}$ & 0.998 & & 3.7 & 4.2 \\
\hline 5-HT & $\begin{aligned} A= & 0.8592 \mathrm{c}+ \\
& 28.15\end{aligned}$ & 0.997 & & 0.9 & 3.6 \\
\hline DOPAC & $\begin{aligned} \mathrm{A}= & 0.2679 \mathrm{c}+ \\
& 13.96\end{aligned}$ & 0.997 & & 3.0 & 4.5 \\
\hline 5-HIAA & $\begin{aligned} A= & 0.8471 \mathrm{c}+ \\
& 27.46\end{aligned}$ & 0.999 & & 1.0 & 2.5 \\
\hline HVA & $\begin{aligned} A= & 0.4847 c+ \\
& 27.94\end{aligned}$ & 0.993 & & 1.7 & 4.0 \\
\hline
\end{tabular}

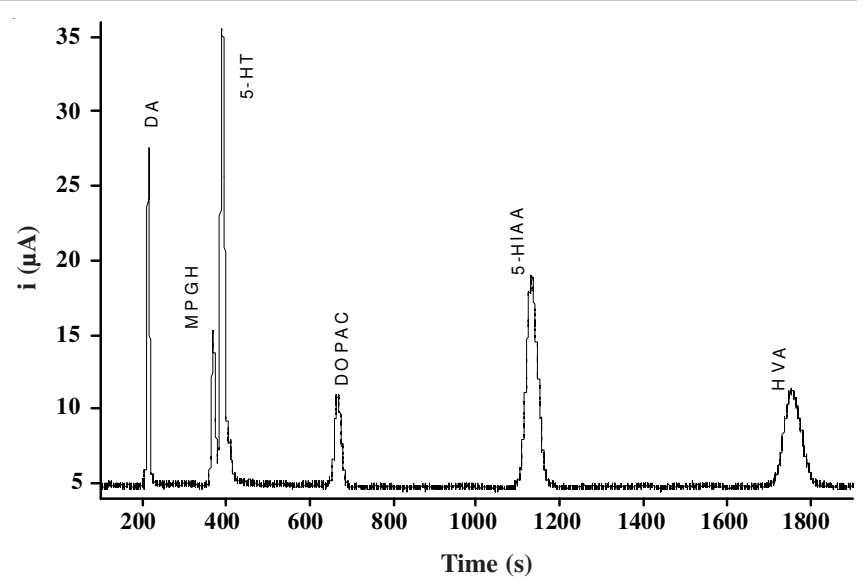

Fig. 4. Standard analytes chromatogram (all $500 \mathrm{ng} \mathrm{mL}^{-1}$ ). Other conditions are as in Fig. 2

Brain samples: The brains were taken out and flushed with $4{ }^{\circ} \mathrm{C}$ physiological saline to wash the blood away, then $1 \mathrm{~mL}$ of $5 \%$ sulfosalicylic acid were added and homogenized with a homogenizer for $5 \mathrm{~min}$ to remove the protein. The pre-treatment was just one step, very sample and then could be detected by the machine. Intra- and inter-day precision were calculated by application to 7 samples spiked with the analytes. Intra- and inter-assay variations determined over a week period were less than $5 \%$. A summary of the results is presented in Table-2. Fig. 5 illustrated a typical neurotransmitters chromatogram of normal mouse brain sample obtained by the present method.

\begin{tabular}{|c|c|c|c|c|c|}
\hline \multicolumn{6}{|c|}{$\begin{array}{c}\text { TABLE-2 } \\
\text { DATA FOR RECOVERY FROM SPIKED BRAIN SAMPLES }\left(n=7^{\llbracket}\right)\end{array}$} \\
\hline \multirow[b]{2}{*}{ Analyte } & \multirow[b]{2}{*}{$\begin{array}{l}\text { Added } \\
(\mathrm{ng} / \mathrm{mL})\end{array}$} & \multicolumn{2}{|c|}{ Intra-day } & \multicolumn{2}{|c|}{ Inter-day } \\
\hline & & $\begin{array}{c}\text { Recovery } \\
(\%)\end{array}$ & $\begin{array}{c}\text { RSD } \\
(\%)\end{array}$ & $\begin{array}{c}\text { Recovery } \\
(\%)\end{array}$ & $\begin{array}{l}\mathrm{RSD} \\
(\%)\end{array}$ \\
\hline \multirow{3}{*}{ DA } & 10 & $92.1 \pm 3.1$ & 3.4 & $90.5 \pm 2.6$ & 2.9 \\
\hline & 100 & $92.5 \pm 3.1$ & 3.3 & $89.3 \pm 3.2$ & 3.6 \\
\hline & 500 & $90.4 \pm 2.6$ & 2.9 & $86.6 \pm 2.2$ & 2.8 \\
\hline \multirow{3}{*}{ MHPG } & 10 & $91.4 \pm 3.4$ & 3.7 & $89.3 \pm 3.9$ & 4.4 \\
\hline & 100 & $92.3 \pm 2.7$ & 2.9 & $90.3 \pm 3.4$ & 3.8 \\
\hline & 500 & $92.0 \pm 2.7$ & 2.7 & $92.6 \pm 2.8$ & 3.1 \\
\hline \multirow{3}{*}{$5-\mathrm{HT}$} & 10 & $94.5 \pm 2.1$ & 2.2 & $91.3 \pm 2.9$ & 3.2 \\
\hline & 100 & $91.7 \pm 2.2$ & 2.4 & $89.7 \pm 2.6$ & 3.0 \\
\hline & 500 & $89.4 \pm 1.8$ & 2.1 & $90.6 \pm 3.0$ & 3.4 \\
\hline \multirow{3}{*}{ DOPAC } & 10 & $91.1 \pm 3.8$ & 4.2 & $91.5 \pm 3.3$ & 3.6 \\
\hline & 100 & $89.5 \pm 4.3$ & 4.8 & $88.3 \pm 4.2$ & 4.8 \\
\hline & 500 & $87.5 \pm 2.6$ & 3.0 & $89.8 \pm 3.2$ & 3.6 \\
\hline \multirow{3}{*}{ 5-HIAA } & 10 & $94.1 \pm 1.8$ & 2.0 & $93.9 \pm 2.8$ & 3.0 \\
\hline & 100 & $93.8 \pm 2.6$ & 2.8 & $93.3 \pm 3.2$ & 3.4 \\
\hline & 500 & $93.8 \pm 3.1$ & 3.3 & $92.6 \pm 3.2$ & 3.4 \\
\hline \multirow{3}{*}{ HVA } & 10 & $89.2 \pm 2.6$ & 2.9 & $90.1 \pm 3.6$ & 4.0 \\
\hline & 100 & $89.8 \pm 3.4$ & 3.8 & $87.3 \pm 4.2$ & 4.8 \\
\hline & 500 & $88.6 \pm 2.0$ & 2.3 & $87.8 \pm 3.0$ & 3.4 \\
\hline
\end{tabular}

"Same sample pretreated by the same process on 7 consecutive days

Application to brain analysis of normal and paraquatinduced mouse: All the mentioned neurotransmitters are important to the mammals, especially the humans. The determinations of healthy/paraquat-induced group results were listed in Table-3.

We found that the concentrations of the six neurotransmitters were decreased as time went by until the $21^{\text {st }}$ day. From Table-3, homovanillic acid and 3-methoxy-4-hydroxy 
TABLE-3

DETERMINATION OF NTs IN CK/PQ-INDUCED MICE'S BRAINS

\begin{tabular}{|c|c|c|c|c|c|c|}
\hline \multirow{2}{*}{ Samples } & \multicolumn{6}{|c|}{ Concentration $(\mathrm{n}=7, \mathrm{ng} / \mathrm{g})^{a}$ and percent $(\%)$} \\
\hline & \multicolumn{2}{|c|}{ DA } & \multicolumn{2}{|c|}{ DOPAC } & \multicolumn{2}{|c|}{ HVA } \\
\hline $\mathrm{CK}$ & $1903 \pm 324$ & $100 \pm 17$ & $96.1 \pm 9.3$ & $100 \pm 10$ & $63.4 \pm 5.3$ & $100 \pm 8$ \\
\hline $1 d$ & $2007 \pm 392$ & $105 \pm 21$ & $91.6 \pm 6.6$ & $95 \pm 7$ & $61.0 \pm 6.6$ & $96 \pm 10$ \\
\hline $3 d$ & $1796 \pm 173$ & $94 \pm 9$ & $88.2 \pm 6.0$ & $92 \pm 6$ & $56.2 \pm 4.6^{*}$ & $89 \pm 7$ \\
\hline $7 d$ & $1458 \pm 183^{\#}$ & $77 \pm 10$ & $80.3 \pm 2.8^{*}$ & $84 \pm 3$ & $44.1 \pm 4.7^{*}$ & $70 \pm 7$ \\
\hline $14 d$ & $1509 \pm 276^{\#}$ & $79 \pm 15$ & $76.6 \pm 5.1^{*}$ & $80 \pm 5$ & $39.5 \pm 5.8^{*}$ & $62 \pm 9$ \\
\hline $21 d$ & $1461 \pm 245^{\#}$ & $77 \pm 13$ & $79.2 \pm 6.9^{*}$ & $82 \pm 7$ & $36.8 \pm 6.6^{*}$ & $58 \pm 10$ \\
\hline Samples & \multicolumn{2}{|c|}{ MHPG } & \multicolumn{2}{|c|}{ 5-HT } & \multicolumn{2}{|c|}{ 5-HIAA } \\
\hline CK & $322 \pm 17$ & $100 \pm 5$ & $86.1 \pm 8.5$ & $100 \pm 10$ & $63.3 \pm 5.3$ & $100 \pm 9$ \\
\hline $1 d$ & $315 \pm 13$ & $98 \pm 4$ & $87.1 \pm 10.1$ & $101 \pm 12$ & $64.0 \pm 6.4$ & $101 \pm 10$ \\
\hline $3 d$ & $293 \pm 11^{*}$ & $91 \pm 3$ & $78.3 \pm 8.1$ & $91 \pm 9$ & $59.4 \pm 5.3$ & $94 \pm 8$ \\
\hline $7 d$ & $288 \pm 13^{*}$ & $89 \pm 4$ & $72.0 \pm 5.7^{\#}$ & $84 \pm 7$ & $58.4 \pm 5.8$ & $92 \pm 9$ \\
\hline $14 d$ & $278 \pm 11^{*}$ & $86 \pm 3$ & $66.3 \pm 8.3^{*}$ & $77 \pm 10$ & $53.8 \pm 5.8^{*}$ & $85 \pm 9$ \\
\hline $21 \mathrm{~d}$ & $275 \pm 9^{*}$ & $85 \pm 3$ & $69.7 \pm 11.7^{\#}$ & $81 \pm 14$ & $52.9 \pm 9.8^{\#}$ & $84 \pm 15$ \\
\hline
\end{tabular}

phenylglycol were significantly reduced at $3^{\text {rd }}$ day and they remained $58 \%$ and $85 \%$ at $21 \mathrm{~d}(\mathrm{P}<0.01)$. 3,4-Dihydroxyphenylacetic acid is the metabolite of dopamine, while 5-hydroxyindole-3-acetic acid is the metabolite of 5-hydroxytryptamine. The variation tends of prototypes and their metabolites were the same in this experiment. The dopamine and 3,4-dihydroxyphenylacetic acid were significantly reduced at $7^{\text {th }}$ day, they remained $77 \%$ and $82 \%$ at $21 \mathrm{~d}(\mathrm{P}<0.05, \mathrm{P}<$ $0.01)$. While 5-hydroxytryptamine and 5-hydroxyindole-3acetic acid were significantly reduced at $7^{\text {th }}$ and $14^{\text {th }}$ day, respectively, they remained $81 \%$ and $84 \%$ at $21 \mathrm{~d}(\mathrm{P}<0.05)$.

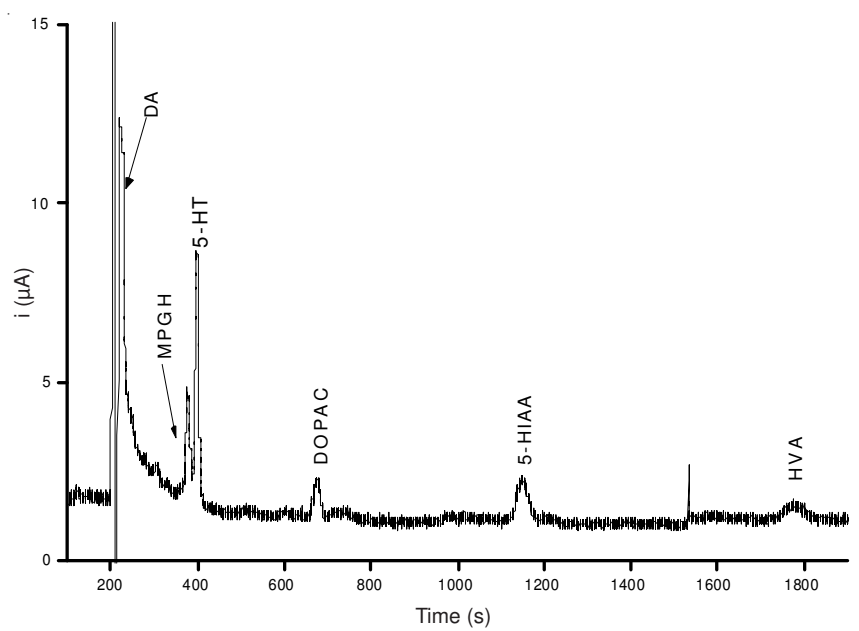

Fig. 5. Target analytes chromatogram of a normal mouse brain. Other conditions are as in Fig. 2

The biochemical mechanism of paraquat toxicity is due to the cyclic oxidation and reduction in tissues, leading to production of superoxide anion and other free radicals and eventually the highly destructive hydrogen peroxide ${ }^{15-17}$. However in mammal brains, the delivery of neurotransmitters depends on huge amounts of free electrons and varieties of enzymes. While paraquat arrives at brain as the blood circulation, oxidation occurs, causing tissue damage and death. Paraquat oxidation is coupled with the reduction of molecular oxygen, forming superoxide anion, on further oxidation, with lipid hydroxyl radicals. Various enzymes in the brain cells catabolize the superoxide radical and reduce the lipid hydroperoxides to less-toxic lipid alcohols. In addition, in the presence of reduced NADPH, paraquat is reduced by microcsomal NADPH-cytochrome reductase $\mathrm{e}^{16-18}$. Therefore paraquat in brains will cause a serial of reactions, influencing the delivery of neurotransmitters.

\section{Conclusion}

This article has described an LC-ECD method for the simultaneous determination of dopamine, 3,4-dihydroxyphenyl-acetic acid, homovanillic acid, 3-methoxy-4-hydroxy phenylglycol, 5-hydroxytryptamine and 5-hydroxyindole-3-acetic acid in mouse brains. The current results demonstrate that LC-ECD is a suitable alternative to LC-FLD and LC-MS/MS of dansylated neurotransmitters in brain and other biological samples. This method is highly sensitive and selective and can be clinically applied as a biochemical index for certain diseases and the monitoring of drug therapy. In this study, the method was developed to facilitate measurement of patients and during their follow-up.

\section{REFERENCES}

1. E. Koyama, A. Minegiehi and T. Ishizaki, Clin. Chem., 34, 680 (1988).

2. B.S. Meldrum, Epilepsia, 36, S30 (1995).

3. D. Risser, G. Lubec, N. Cairns and M.H. Marschitz, Life Sci., 60, 1231 (1997).

4. H. Mitani, Y. Shirayama, T. Yamada and R. Kawahara, Prog. Neuropsychopharmacol. Biol. Psychiatry, 30, 531(2006).

5. D.J. Zgaljardic, N.S. Foldi and J.C. Borod, J. Neural. Transm., 111, 1287 (2004).

6. J.T. Hughes, Neurotoxicol., 9, 243 (1988).

7. G.S. Liu, J.N. Chen and Y.F. Ma, J. Chromatogr. B, 805, 281 (2004).

8. M.A. Fotopoulou and P.C. Ioannou, Anal. Chim. Acta, 462, 179 (2002).

9. S.X. Xiong, H.W. Han, R. Zhao, Y. Chen and G.Q. Liu, Biomed. Chromatogr., 15, 83 (2001).

10. S. Ozcan and H.Z. Senyuva, J. Chromatogr. A, 1135, 179 (2006).

11. Y.L. Deng, W. Maruyama, M. Kawai, P. Dostert, H. Yamamura, T. Takahashi and M. Naoi, J. Chromatogr. B, 689, 313 (1997).

12. B.E. Tóth, K. Homicskó, B. Radnai, W. Maruyama, J.E. DeMaria, M. Vecsernyés, M.I. Fekete, F. Fülöp, M. Naoi, M.E. Freeman and G.M. Nagy, J. Neuroendocrinol., 13, 1042 (2001).

13. W. Zhang, Y.F. Xie and L.T. Jin, J. Chromatogr. B, 791, 217 (2003).

14. M.A. Raggi, C. Sabbioni, G. Casamenti, G. Gerra, N. Calonghi and L. Masotti, J. Chromatogr. B, 730, 201 (1999).

15. J.S. Bus, S.D. Aust and J.E. Gibson, Res. Communic. Chem. Pathol. Pharmacol., 11, 31 (1975).

16. M. Comporti, Chem. Biol. Interact., 72, 1 (1989).

17. T.E. Gram, Pharmacol. Rev., 49, 297 (1997).

18. J.S. Bus and J.E. Gibson, Environ. Health Perspect., 55, 37 (1984). 